\title{
EXPERIMENTAL AND NUMERICAL STUDY OF LOCAL STABILITY OF NON-STANDARD THIN-WALLED CHANNEL BEAMS
}

\author{
Michą Grenda, Piotr Paczos \\ Poznan University of Technology, Institute of Applied Mechanics, Poznan, Poland \\ e-mail: michal.grenda@icloud.com
}

\begin{abstract}
The subject of the paper are cold-formed, thin-walled non-standard channel beams with stiffened webs. The local elastic buckling and limit load of the beams subjected topure bending are investigated. This study includes numerical, based on the Finite Element Method and the Finite Strip Method, calculations and actual tests of beams in the laboratory. The presented results give a deep insight into behaviour of such beams and may be used to validate analytical models.
\end{abstract}

Keywords: thin-walled beams, experimental investigation, numerical investigations, pure bending

\section{Introduction}

In the paper, results of numerical analyses and experimental investigations of cold-formed, thin-walled beams with non-standard cross-sections are presented. Thin-walled cold-formed steel beams with open cross-section have become more and more common structural elements which are used in a wide range of applications: civil engineering, automotive industry, aviation, vessel industry and railway industry. Their cross-sections may have complicated shapes that can be made thanks to the development in manufacturing and material technologies. This study includes numerical analyses, based on the FEM, the FSM and experimental investigations. The local elastic buckling and limit load of the beams subjected to pure bending are investigated. The obtained results are compared with the experimental findings helps one to improve mathematical models of beams.

Researches on thin-walled structures have been conducted for many years. The number of works devoted to the theory of thin-walled structures has been steadily growing. Materials that are used for building modern structures make it possible to reduce their weight for heavier loads. Cold-formed thin-walled beams tend to buckle locally due to the high ratio of transverse dimensions to wall thickness. Therefore, it is justified to look for new shapes of cross-sections that would increase the strength and stability of beams. Some of them have focused on experimental investigations, others on analytical models.

Bambach (2009) considered compressed channel sections with flange edge stiffeners. He compared the results of tests with the recently modified effective width method and the direct strength method. Similar investigations were conducted by Pastor and Roure (2016). The results of experimental investigations of thin-walled beams were presented by Paczos (2014), Biegus and Czepiżak (2008), Yu and Schafer (2007), Mahendran and Jeyaragan (2008). Kwon et al. (2009) described compression tests of cold-formed simple lipped channels and lipped channels with intermediate stiffeners in flanges and the web made of high strength steel plate. More information on local stability and experimental investigations of cold-formed thin-walled C-beams done in this unit may be found in Obst et al. (2016). 
This work is devoted to thin-walled channel beams with non-standard flange beams made of a cold-rolled steel sheet - double box flange beams with a stiffened web (Fig. 1). The local elastic buckling and limit load of these beams in pure bending state is investigated. This is a part of broader research on thin-walled beams and search for new shapes of cross-sections that would increase the strength and stability of beams. The study includes laboratory tests on beams. The beams have been experimental tested in accordance with the Eurocode 3 (2006).

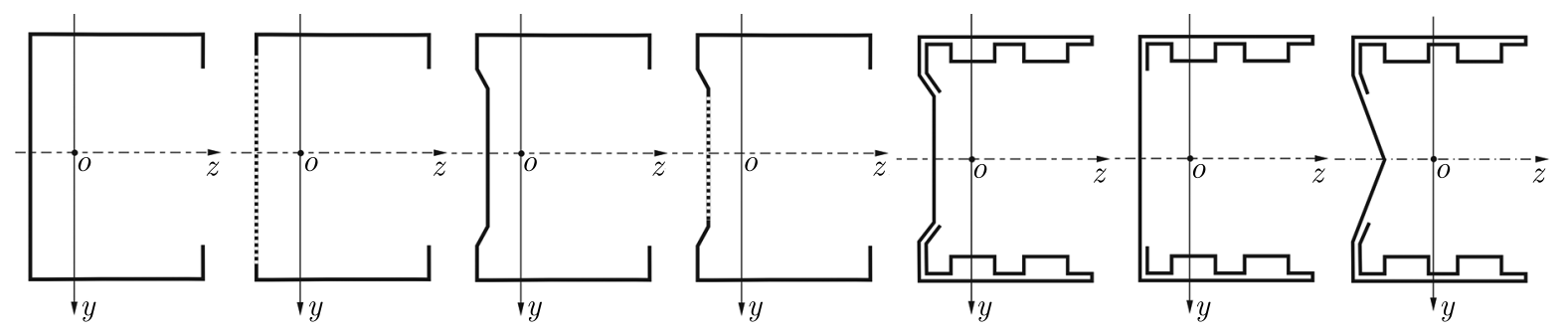

Fig. 1. The investigated cross-section of non-standard channel beams

\section{Description of the investigated cross-sections}

Two thin-walled channel beams B1-V and B2-S with a stiffened web are the subject of investigations. Over 80 samples of different thin-walled beams with non-standard cross-sections have been examined. This work presents the results of experimental investigations carried out 5 times for each cross-section. The results presented in this paper are selected average results from experimental and numerical investigations. The experimental results of pure bending were repeatable for each cross-sections of non-standard thin-walled channel beams.

The experimental investigations were conducted at the Laboratory of Strength of Materials that is a part of Institute of Applied Mechanics at Poznan University of Technology (Poland). The investigated beams were cold-formed and made of steel sheets DX51 by a Polish company.

\subsection{Geometrical properties}

The cross-sections of the investigated beams are presented in Fig. 2. The dimensions of beams are denoted by depth $H=160 \mathrm{~mm}$, width $b=80 \mathrm{~mm}$, wall thickness $t=1.00 \mathrm{~mm}$, other dimensions are shown in Table 1.

(a)

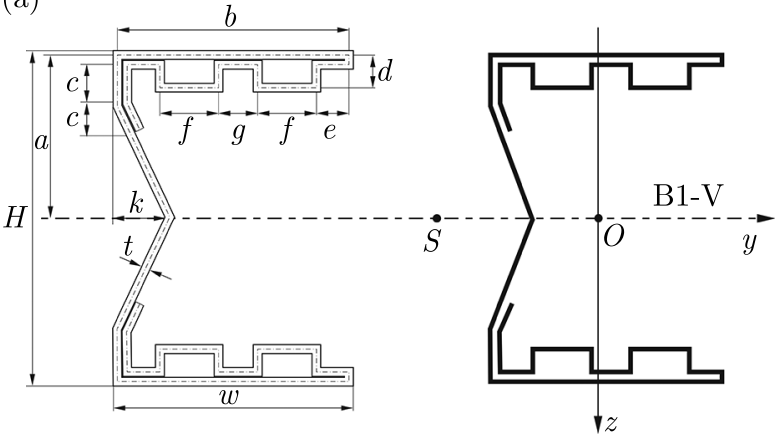

(b)

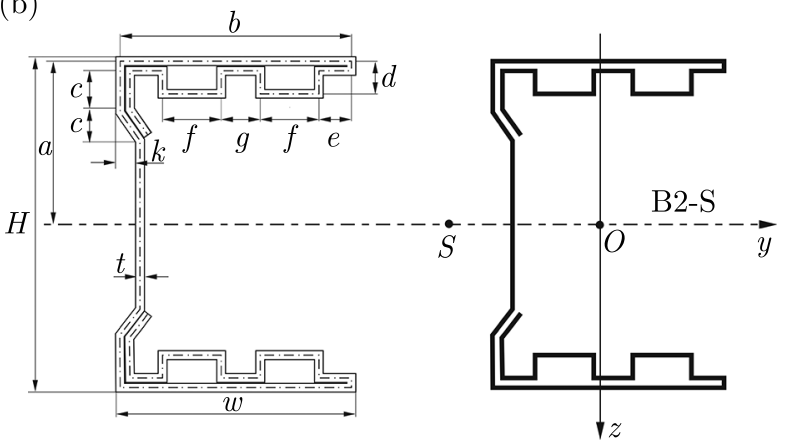

Fig. 2. The cross-sections of tested beams: (a) B1-V, (b) B2-S

The investigated beams have unconventional cross-sections, therefore, the following nomenclature for denoting them is introduced:

- Beams with stiffened web - B1-V,

- Beams with stiffened web-B2-S. 
Table 1. Dimensions of beams

\begin{tabular}{|l|c|c|c|}
\hline \multirow{2}{*}{ Geometric properties } & \multirow{2}{*}{ Dimension } & \multicolumn{2}{|c|}{ Cross-section [mm] } \\
\cline { 3 - 4 } & & beam B1-V & beam B2-S \\
\hline \hline depth of beam & $H$ & 160 & 160 \\
\hline width of flange & $b$ & 80 & 80 \\
\hline wall thickness & $t$ & 1.00 and 1.25 & 1.00 and 1.25 \\
\hline total length of beam & $L_{c}$ & 2000 & 2000 \\
\hline length of the middle span & $L$ & $400,500,600$ & $400,500,600$ \\
\hline distance between supports & $L_{0}$ & 1960 & 1960 \\
\hline length of stiffeners & $L_{S}$ & $780,730,680$ & $780,730,680$ \\
\hline height of stiffeners & $c$ & 26.5 & 26.5 \\
\hline height of flanges & $d$ & 17 & 17 \\
\hline dimensions & $e$ & 14 & 14 \\
\hline width of boxes & $f$ & 18 & 18 \\
\hline distance between boxes & $g$ & 14 & 14 \\
\hline dimensions & $k$ & $5-50$ & $5-50$ \\
\hline
\end{tabular}

Small differences between some dimensions (Table 1) are a result of manufacturing problems with cold-rolling of the presented beams. The subjects of the investigation are non-standard thin-walled channel C-beams. Thin-walled beams with open cross sections are used in mechanical and civil engineering. In numerical analyses, the length $L$ is 400, 500 and $600 \mathrm{~mm}$. In the actual beams the length $L$ is equal to $500 \mathrm{~mm}$. Normal stresses at the center of the upper flange (top steel sheet) are equal to

$$
\sigma_{g}=\frac{M_{g}}{J_{y}} \frac{H-t}{2}
$$

where $J_{y}$ is the moment of inertia of the beam cross-section. Pure bending is simulated by four-point bending test in which the endings of a beam are stiffened with steel sheets having better strength properties than the beam. The beam loading scheme and the longitudinal dimensions of the beam are shown in Fig. 3.

The bending moment in the middle span may be calculated in the following way

$$
M_{g}=\frac{1}{2} F L_{S}
$$

After basic transformations and putting equation (2.2) into (2.1), the relationship between the loading force and stresses is

$$
F=\frac{4 J_{y} \sigma_{g}}{(H-t) L_{S}}
$$

where: $M_{g}$ - critical bending moment, $F$ - critical force, $L_{S}$ - distance between applied force and support (Fig. 3), $H$ - depth of beam, $t$ - wall thickness, $J_{y}$ - section modulus, $\sigma_{g}$ - boundary stress.

The markes dimensions are following:

- total length $L_{c}=2000 \mathrm{~mm}$,

- distance between the supports $L_{0}=1960 \mathrm{~mm}$,

- distance between the applied force and support $L_{S}=730 \mathrm{~mm}$,

- length of the middle span subjected to pure bending $L=500 \mathrm{~mm}$. 

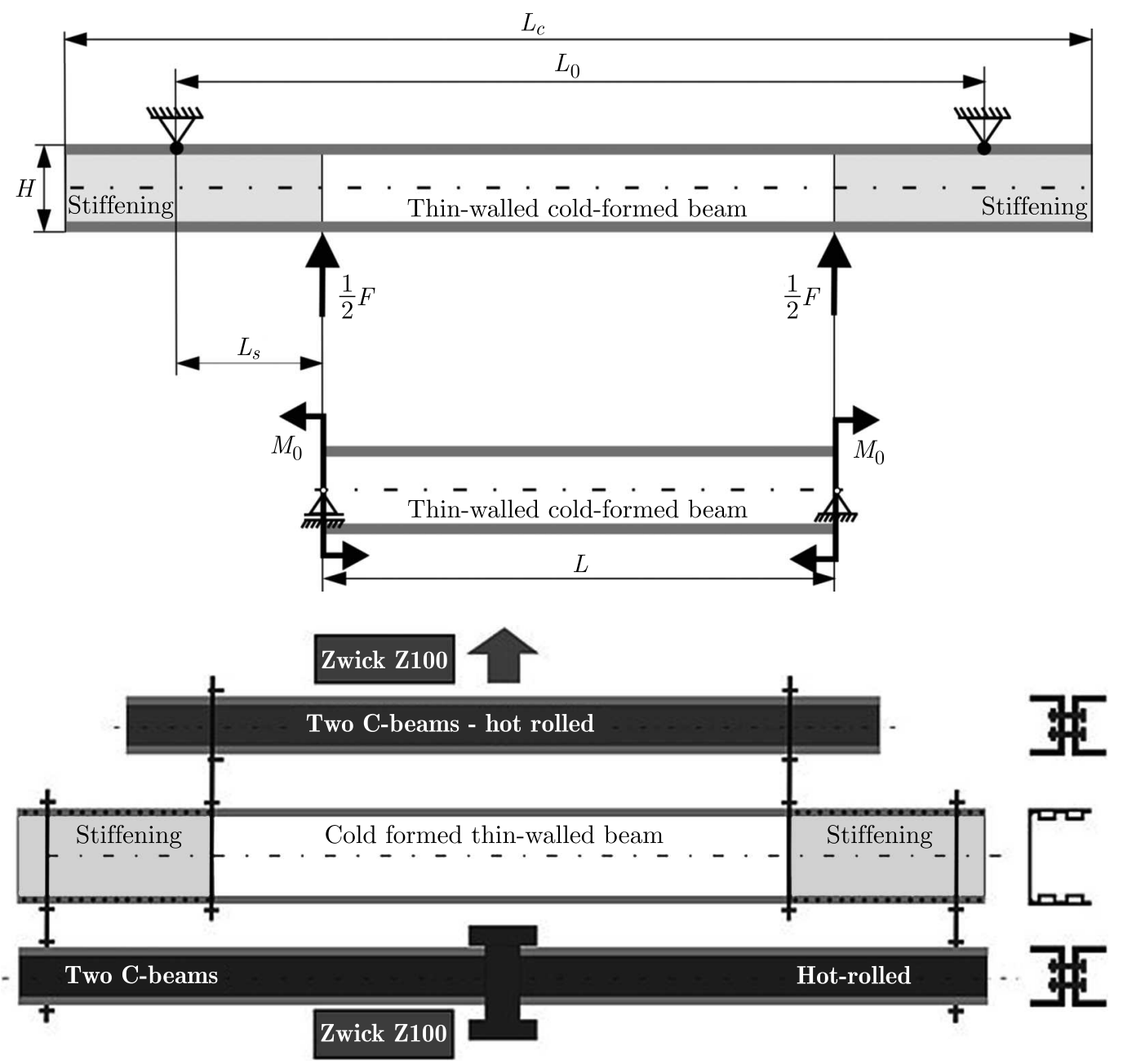

Fig. 3. Loading scheme and longitudinal dimensions of the beam

\subsection{Material properties}

The channel beams with non-standard open cross-sections were made of steel sheet DX51 with wall thikness $t=1.00 \mathrm{~mm}$, hot-dip galvanized, zinc coating Z200-200 g/m² (Z200 according to EN 10025-2:2007). The corrugations are not connected to the sheets in any way. During the production of beams, no separable and non-separable connections were used. The thin-walled structures were produced only by cold rolling from one piece of sheet metal. The beams were cold-formed using a CNC cold rolling machine, according to Eurocode 3 (2006).

The material properties were measured by testing specimens cut from the beams (Fig. 4). They were determined by testing 5 samples prepared according to Eurocode 3 (2006). The results are following: $E=181 \mathrm{GPa}, \nu=0.3, R_{e H}=330 \mathrm{MPa}, R_{m}=380 \mathrm{MPa}$. The results of tensile tests were presented in the paper (Paczos, 2013).

\section{Numerical analysis - the Finite Element Method}

In this Section, the results of finite element analyses are presented. They were done to determine critical forces and buckling modes of beams shown in Fig. 2.

There is a lot of papers devoted to finite element analyses of thin-walled structures that confirm that this is still an interesting subject for researchers. It is caused by the fact that 


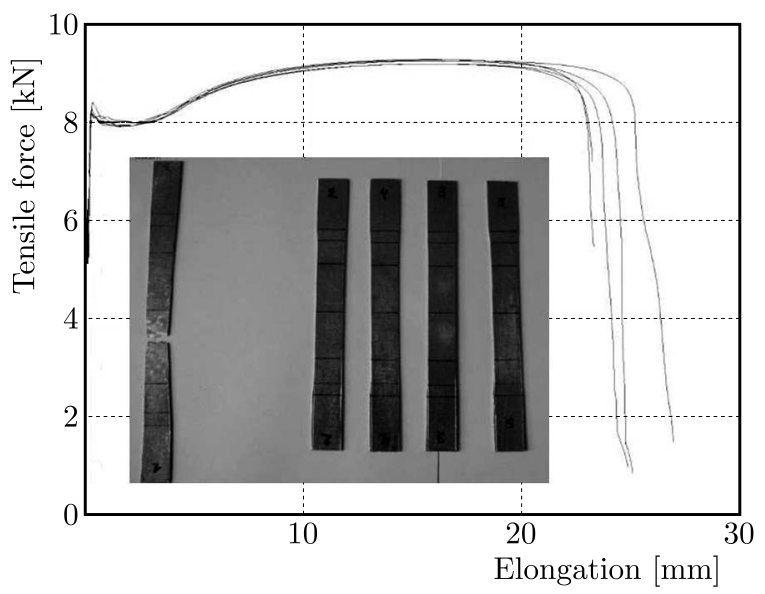

Fig. 4. The stress-strain curve of specimens - steel DX51

the FEM provides a good insight into behaviour of such structures. However, it is important that numerical results are compared with and validated by actual tests. An example of such works on thin-wall channel beams is Gonçalves et al. (2010). The authors presented a kinematic description of thin-walled beams and they assumed large displacements. Their model included rotation and deformation of cross-section such as deflection of walls. They presented a few samples and compared their results with a standard analytical model. Ibrahim et al. (2012) proposed a 1D finite shell element that can be used for modelling buckling of thin-walled beams using higher order ( $N$-order) theories. They analysed the stability of beams with boxed flanges, I-beams, thin plates and tubes that were simply supported and clamped. The obtained results, i.e. critical forces and buckling modes, were compared with the results of other authors that based their models on EBBT: Euler-Bernoulli Beam Theory; TBT: Timoshenko Beam Theory. Problems presented in this work refer to the strength and stability of beams subjected to fourpoint bending, i.e. the authors were interested in the distribution of stresses in flanges and the web, deflection of beams and critical forces.

Models shown in Fig. 5 are prepared in SolidWorks (2012), a popular CAD system. It is a practical aspect of those investigations, which proves that common CAD software used by engineers all over the world can successfully model such problems.

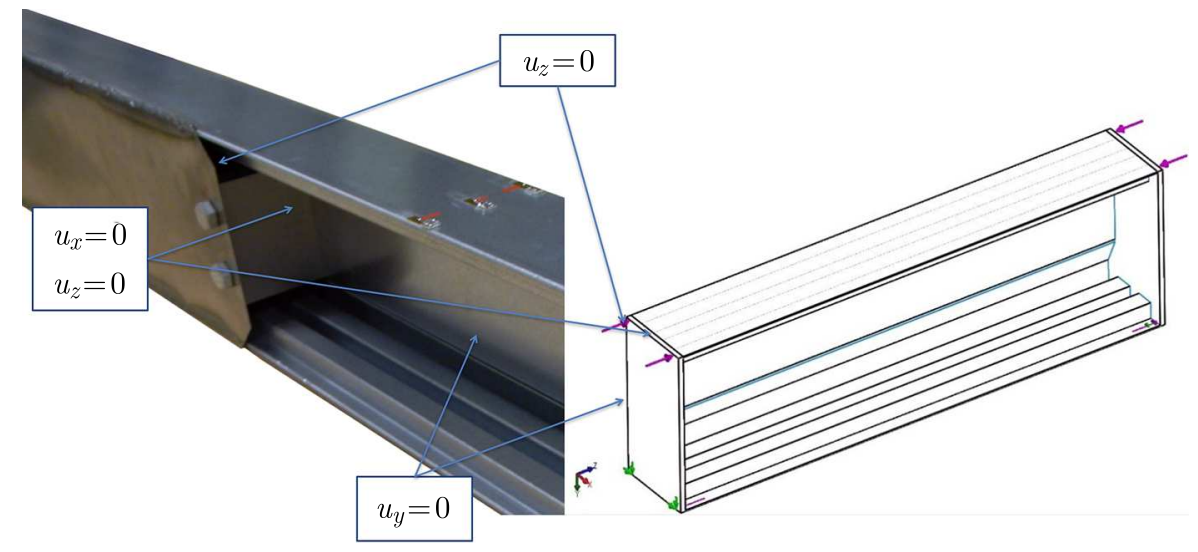

Fig. 5. Schematic diagram of boundary conditions marked with green arrows and loads marked with pink arrows (only the middle span is modelled)

Particularly difficult is the modelling of boundary conditions of the corresponding terms in other ways, for example analytical or numerical the FSM. In this study, it is noted that the support conditions in the numerical model were as was described with the experimental 
investigation. The beams are simply supported. These boundary conditions are modelled by locking translation in all three directions at one bottom edge and in two directions (vertical and transverse ones) at another bottom edge. The schematic diagram of those boundary conditions is shown in Fig. 5.

The bending moment in the middle span of beam that is subjected to a four-point bending test is constant. This is modelled by applying compression forces to the top edge of stiffeners and tension forces to their bottom edges. These forces are parallel to the axis of beam and equal to $1 \mathrm{~N}$. Thus, the obtained dimensionless buckling factor is equal to the critical force.

In thin-walled beams, the ratio of wall thickness to the dimensions of cross-section is small. Therefore, finite shell elements are used for meshing a beam, because in this case they give more accurate results than solid finite elements. The latter can be used when the ratio between transverse and longitudinal dimensions is within $1: 1$ to $1: 5$. If this ratio is approximately 1:10, shell elements seems to be a more efficient and accurate choice. This assumption was checked and validated by Ibrahim et al. (2012). In this paper, the authors use the 2 nd order triangular finite elements. The mesh in the stiffened part of the web is finer to improve numerical calculations. The maximum size of finite elements in this region is $5 \mathrm{~mm}$. Choice of the mesh is preceded by convergence analysis. The results for a mesh finer than $5 \mathrm{~mm}$ differ by less than $3 \%$. The used mesh is shown in Fig. 6.

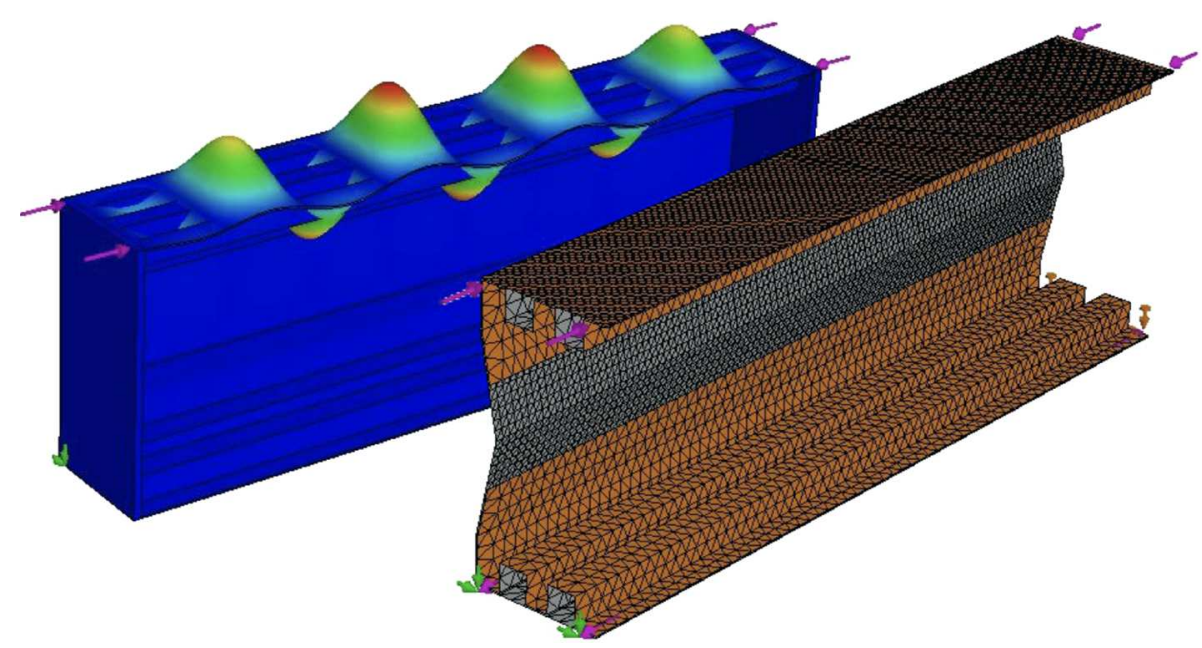

Fig. 6. The used finite element mesh of beams and the linear buckling mode (only the middle span is modelled)

At the beginning, to validate the numerical model, i.e. loads, boundary conditions and material properties, linear static analysis was done. Stress distribution and deformation of beams were corrected and as expected. Next, stability analysis was conducted. The calculated buckling modes of the top compressed flanges are presented in Fig. 6.

The calculated critical forces of beams B1-V and B2-S (wall thickness $t=1.00 \mathrm{~mm}$ ) are equal to $15.9 \mathrm{kN}$ and $16.9 \mathrm{kN}$, respectively. In both cases, they all refer to the first eigenvalue. The aim of this numerical research is comparison of the results with the experimental ones and the numerical from the Finite Strip Method described in the next paragraph. In that way, the numerical model can be validated.

\section{Numerical analysis - the Finite Strip Method}

Adany and Schafer (2006) presented a method for calculating critical loads of thin-walled beams based on the Finite Strip Method (FSM). They made the decomposition of buckling modes 
using the Generalized Beam Theory (GBT) that helps distinguishing them from each other. Li and Schafer (2010) showed another way to determine elastic critical loads used for calculating limit loads in the Direct Strength Method (DSM). They proposed calculating the values of those forces that agreed with the values obtained using the standard FSM for lengths of half-waves derived from the cFSM for pure buckling modes. The reason of this new approach was the lack of unambiguous minima for local and distortional buckling modes. At the end, the authors compared the new method of calculating limit loads using the DSM with standard ones and another proposed by Beregszászi and Ádány (2009). Adany et al. (2010) presented a method for determining buckling modes using the cFSM and implemented in software the CuFSM.

Djafour et al. (2010) improved the constrained finite strip method by simplifying the derivation of the constraint matrix in the case of combined global and distortional buckling modes. This led to a simple and systematic formulation which allowed the cFSM to compute pure buckling modes for members with open and closed thin-walled open cross-sections.

Chu et al. (2006) investigated local stability of cold-formed thin-walled Z-channels with stiffened flanges using the Finite Strip Method. They considered simply supported beams subjected to a uniformly distributed load. The obtained results were compared with previous analyses of beams subjected to pure bending. They concluded that the critical moment was higher for the first load case, but the difference between critical forces became smaller for longer beams.

The ratio of wall thickness to transverse dimensions of cold-formed thin-walled beams is small. Therefore, their load capacity is usually limited by stability. They validated and compared theoretical results (critical forces and buckling modes) with numerical ones using the Finite Strip Method. Paczos (2013) conducted stability analysis of channel beams with boxed flanges using the CuFSM and compared the obtained results with actual experiments.

The results, i.e. critical forces and stresses and respective buckling modes obtained using the Finite Strip Method, are compared and presented in tables and figures in the next paragraphs. The number of half-waves depending on the shape of cross-section, web stiffeners and wall thicknesses are also compared. The beams consist of 30 strips and they are loaded in such a way that actual critical forces are equal to calculated load factors multiplied by 100 . Some calculations were repeated by doubling and quadrupling the number of strips to check the numerical results. The best results were achieved when the beams consisted of 120 strips. However, the total time of calculations and differences between the results are also considered.

\subsection{The analysis of beam B1-V with stiffened web}

The cross-section of beam B1-V is presented in Fig. 2. The boxed flanges significantly improve the load capacity, strength and stability of the beam without increasing its weight too much.

The moment of inertia of beam B1-V is equal to $J_{y}=317.5 \mathrm{~cm}^{4}$ and $J_{y}=396.9 \mathrm{~cm}^{4}$ for the wall thickness $t=1.00 \mathrm{~mm}$ and $t=1.25 \mathrm{~mm}$, respectively. The relationship between the load factor and length of half-wave and the buckling mode of beam B1-V (the FSM) are shown in Fig. 7.

The calculated values of critical stresses and forces and the number of half-waves are presented in Tables 2 and 3. As mentioned earlier, three different lengths of the middle span are considered (Fig. 3) and two different wall thicknesses (Table 2, $t=1.00 \mathrm{~mm}$ and Table 3, $t=1.25 \mathrm{~mm})$.

\subsection{The analysis of beam B2-S with stiffened web}

The cross-section of beam B2-S is presented in Fig. 2. The boxed flanges significantly improve the load capacity, strength and stability of beam without increasing its weight too much. Moreover, the stiffeners in the web make it stiffer and less prone to buckling. 


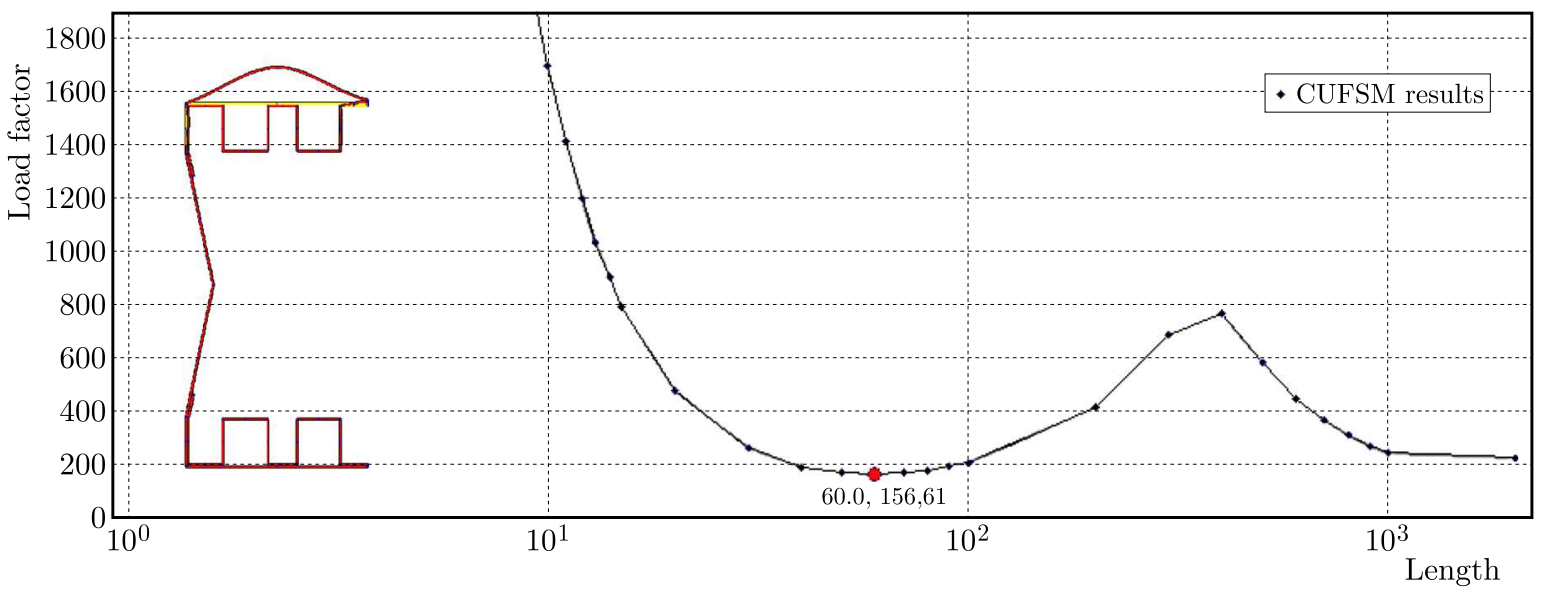

Fig. 7. Beam B1-V, L $=500 \mathrm{~mm}$ : the relationship between the length of half-wave and the load factor

Table 2. Beam B1-V, $t=1.00 \mathrm{~mm}$ : critical stresses and forces

\begin{tabular}{|c|c|c|c|}
\hline & \multicolumn{3}{|c|}{$L[\mathrm{~mm}]$} \\
\cline { 2 - 4 } & 400 & 500 & 600 \\
\hline \hline$\sigma_{C r}[\mathrm{MPa}]$ & 161.5 & 156.3 & 160.0 \\
\hline$F_{C r}[\mathrm{kN}]$ & 16.5 & 16.7 & 18.8 \\
\hline number of half-waves & 6 & 8 & 9 \\
\hline
\end{tabular}

Table 3. Beam B1-V, $t=1.25 \mathrm{~mm}$ : critical stresses and forces

\begin{tabular}{|c|c|c|c|}
\hline \multirow{2}{*}{} & \multicolumn{3}{|c|}{$L[\mathrm{~mm}]$} \\
\cline { 2 - 4 } & 400 & 500 & 600 \\
\hline \hline$\sigma_{C r}[\mathrm{MPa}]$ & 251.2 & 242.2 & 248.3 \\
\hline$F_{C r}[\mathrm{kN}]$ & 32.1 & 33.1 & 36.5 \\
\hline number of half-waves & 6 & 8 & 9 \\
\hline
\end{tabular}

The moment of inertia of beam B2-S is equal to $J_{y}=321.2 \mathrm{~cm}^{4}$ and $J_{y}=401.5 \mathrm{~cm}^{4}$ for the wall thickness $t=1.00 \mathrm{~mm}$ and $t=1.25 \mathrm{~mm}$, respectively.

The relationship between the load factor and length of half-wave and the buckling mode of beam B2-S (the FSM) are shown in Fig. 8.

The calculated values of critical stresses/forces and the number of half-waves are presented in Tables 4 and 5. As mentioned earlier, three different lengths of the middle span are considered (Fig. 3) and two different wall thicknesses (Table $4, t=1.00 \mathrm{~mm}$ and Table $5, t=1.25 \mathrm{~mm}$ ).

The comparison of the relationships between the load factor and the length of half-wave for beams B1-V and B2-S $(t=1.00 \mathrm{~mm})$ is shown in Fig. 9.

The influence of wall thickness $t$ on the relationship between the load factor and the length of half-wave for beam B1-V is presented in Fig. 10 and for beam B2-S in Fig. 11.

It may be concluded that the web stiffeners improve stiffness and stability of the beams (Tables 2-5). The critical forces increase slightly with length of the middle span $L$. However, the parameter $L$ in the considered range has virtually no influence on the critical stresses (less than $3 \%$ ), but the longer is the middle span the more half-waves are observed. Other parameters such as wall thickness and web stiffness have no influence on the number of half-waves. Numerical analyses make it possible to observe the interaction between different buckling modes of flanges and the web. Moreover, they help one to build more accurate analytical models. The obtained results justify the search for new, other than normalized cross-sections of cold-formed thin-walled beams. 


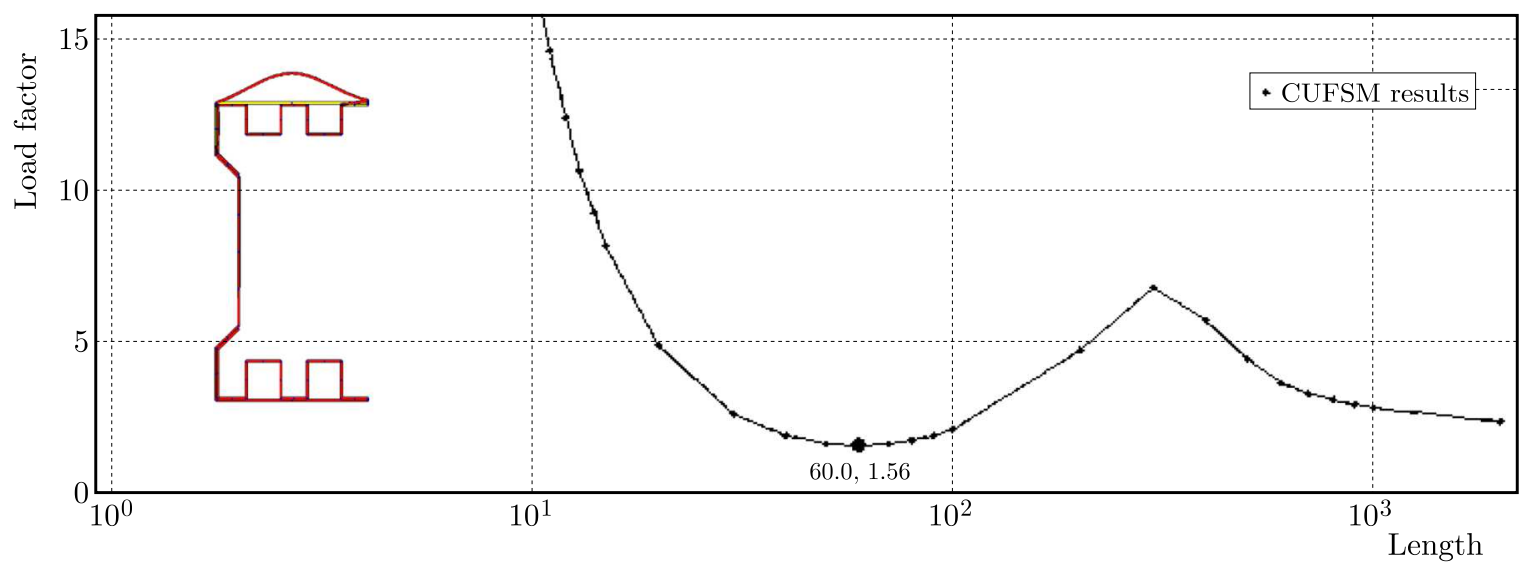

Fig. 8. Beam B2-S, $L=500 \mathrm{~mm}$ : the relationship between the length of half-wave and the load factor

Table 4. Beam B2-S, $t=1.00 \mathrm{~mm}$ : critical stresses and forces

\begin{tabular}{|c|c|c|c|}
\hline \multirow{2}{*}{} & \multicolumn{3}{|c|}{$L[\mathrm{~mm}]$} \\
\cline { 2 - 4 } & 400 & 500 & 600 \\
\hline \hline$\sigma_{C r}[\mathrm{MPa}]$ & 161.3 & 156.2 & 161.5 \\
\hline$F_{C r}[\mathrm{kN}]$ & 16.7 & 17.2 & 19.2 \\
\hline number of half-waves & 6 & 8 & 9 \\
\hline
\end{tabular}

Table 5. Beam B2-S, $t=1.25 \mathrm{~mm}$ : critical stresses and forces

\begin{tabular}{|c|c|c|c|}
\hline & \multicolumn{3}{|c|}{$L[\mathrm{~mm}]$} \\
\cline { 2 - 4 } & 400 & 500 & 600 \\
\hline \hline$\sigma_{C r}[\mathrm{MPa}]$ & 251.2 & 243.1 & 251.0 \\
\hline$F_{C r}[\mathrm{kN}]$ & 32.5 & 33.6 & 37.3 \\
\hline number of half-waves & 6 & 8 & 9 \\
\hline
\end{tabular}

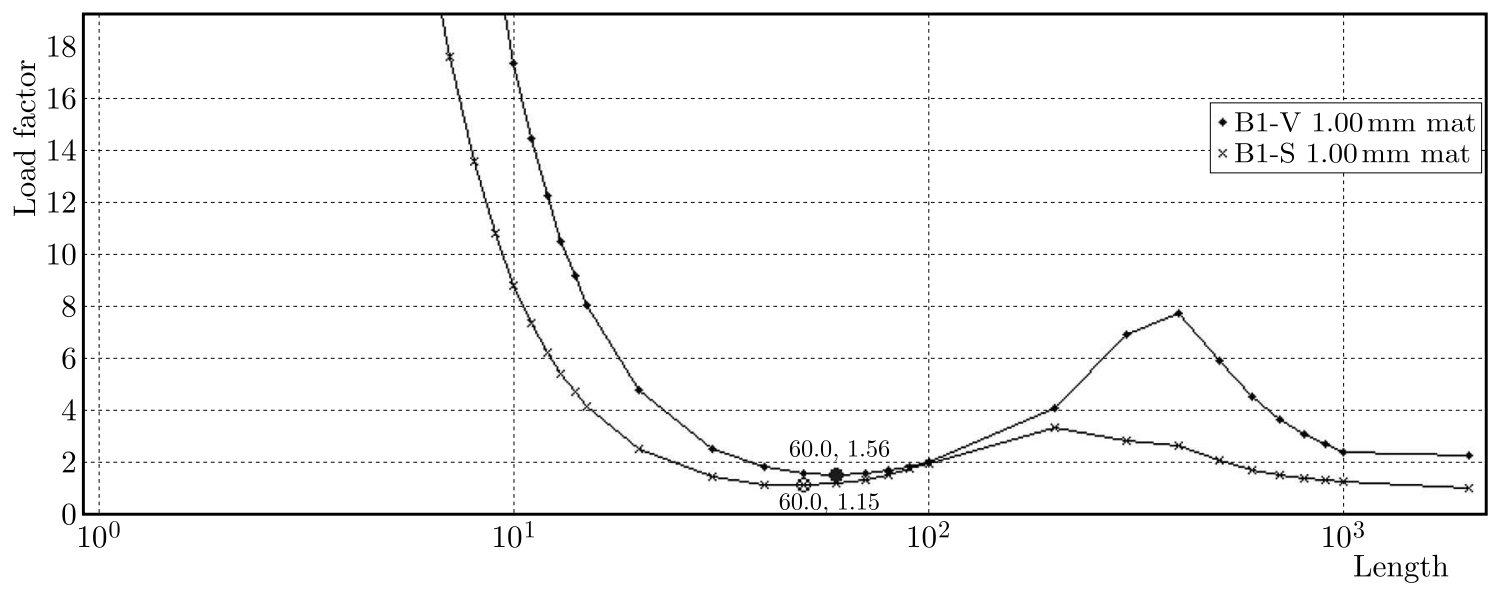

Fig. 9. Beams B1-V and B2-S, $L=500 \mathrm{~mm}, t=1.00 \mathrm{~mm}$ : the relationship between the length of half-wave and the load factor 


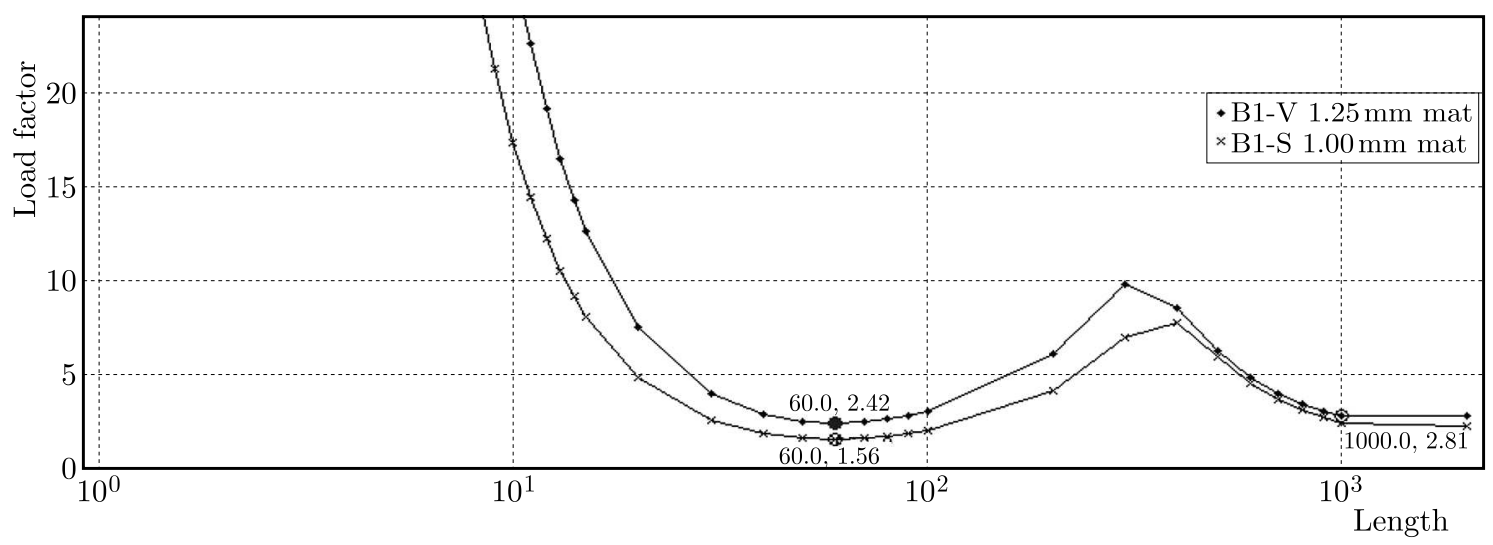

Fig. 10. Beam B1-V, $L=500 \mathrm{~mm}$ : the relationship between the length of half-wave and the load factor

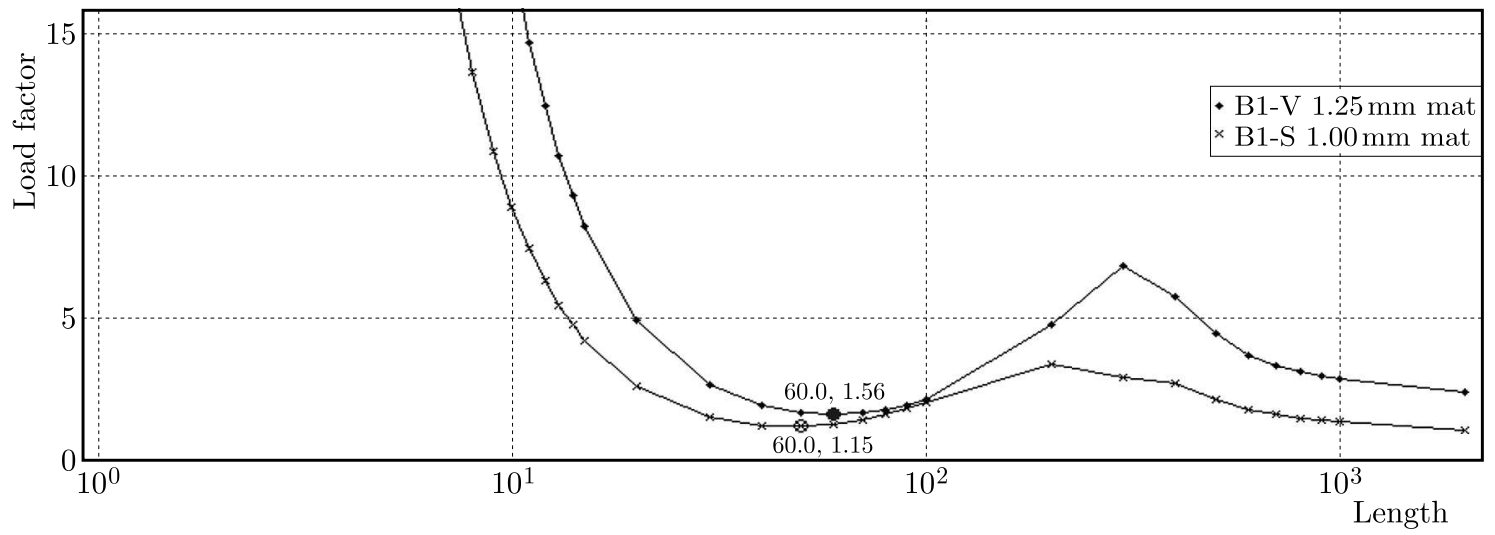

Fig. 11. Beam B2-S, $L=500 \mathrm{~mm}$ : the relationship between the length of half-wave and the load factor

\section{Experimental investigation}

\subsection{Testing equipment}

The presented experimental investigations have been conducted in order to check and validate the analytical models of the local buckling of beams. The locations of strain gauges and deflection sensors are shown in Fig. 12. The strain gauge $A$ is placed in the centre of the compression flange of the beam to measure its deformation and determine the local critical force. The strain gauges $B$ and $C$ are placed on the web. The strain gauge $D$ measures strains in the neutral axis. If the beam is subjected to pure bending, strains in the neutral axis should be equal to zero (Fig. 13). So this strain gauge is used to check, if there is no rotation of the beam subjected to four-point bending, and pure bending is properly simulated. Moreover, the tested beam should be protected against local deformation, e.g. in the places where the point load is applied or where the beam is supported.

The used test stand consists of a force sensor (measuring range $100 \mathrm{kN}$ ), HBM displacement sensor WI 10, HBM foil strain gauges type 6/120LY11 (resistance $120 \mathrm{~W} \pm 0.35 \%$, gauge factor 2), personal computer with software, SPIDER strain gauge bridge and ZWICK Z100 tensile testing machine (range of testing force $0.2-100 \mathrm{kN}$ ).

\subsection{Strain gauge measurements}

In the presented document, one type of load is considered, i.e. pure bending. There are some guidelines in European standards (Eurocode 3, 2006) what should be the proportions of tested beams and their span. The total length of the beam should be at least 15 times bigger than the 

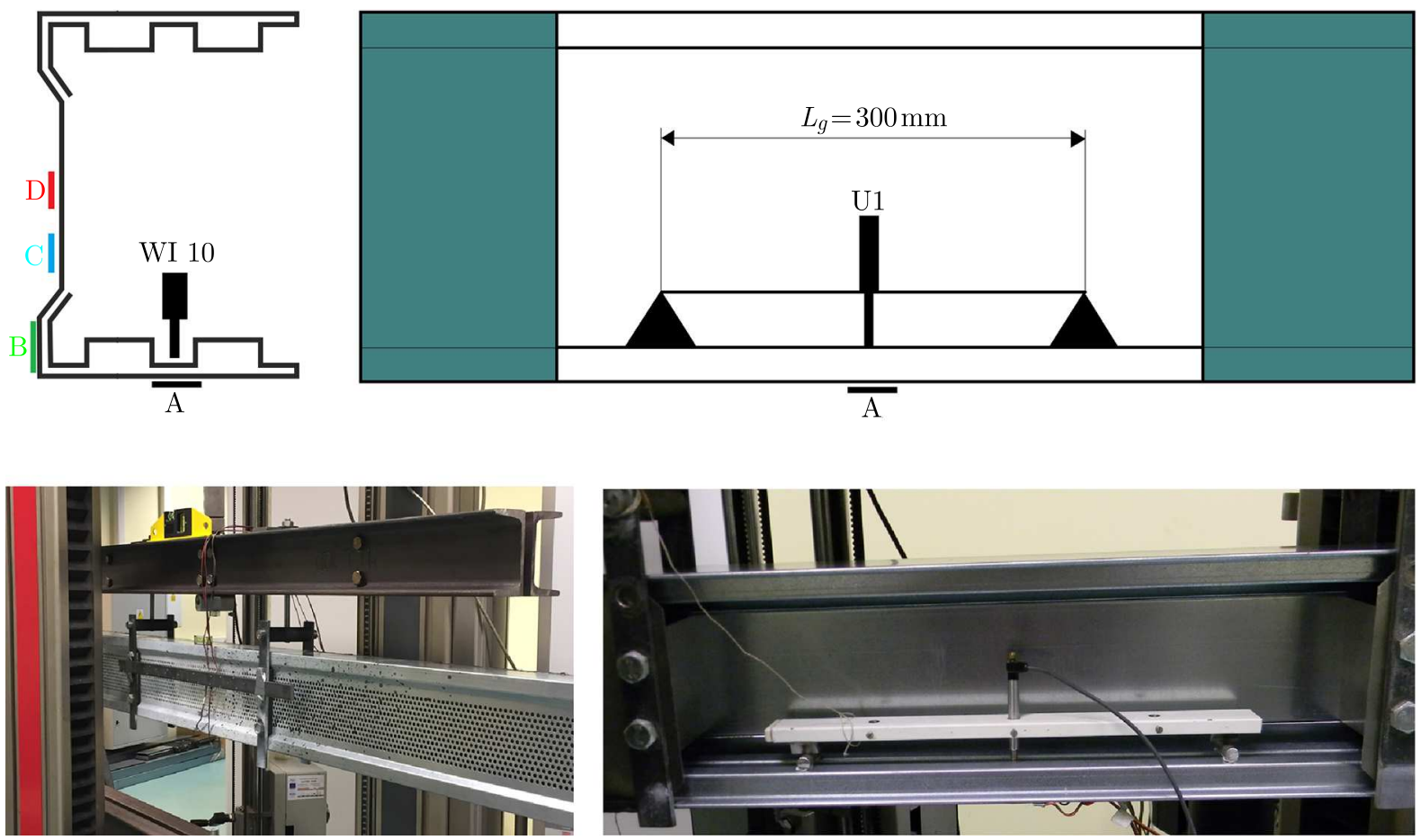

Fig. 12. The investigated beam with strain gauges and the test stand
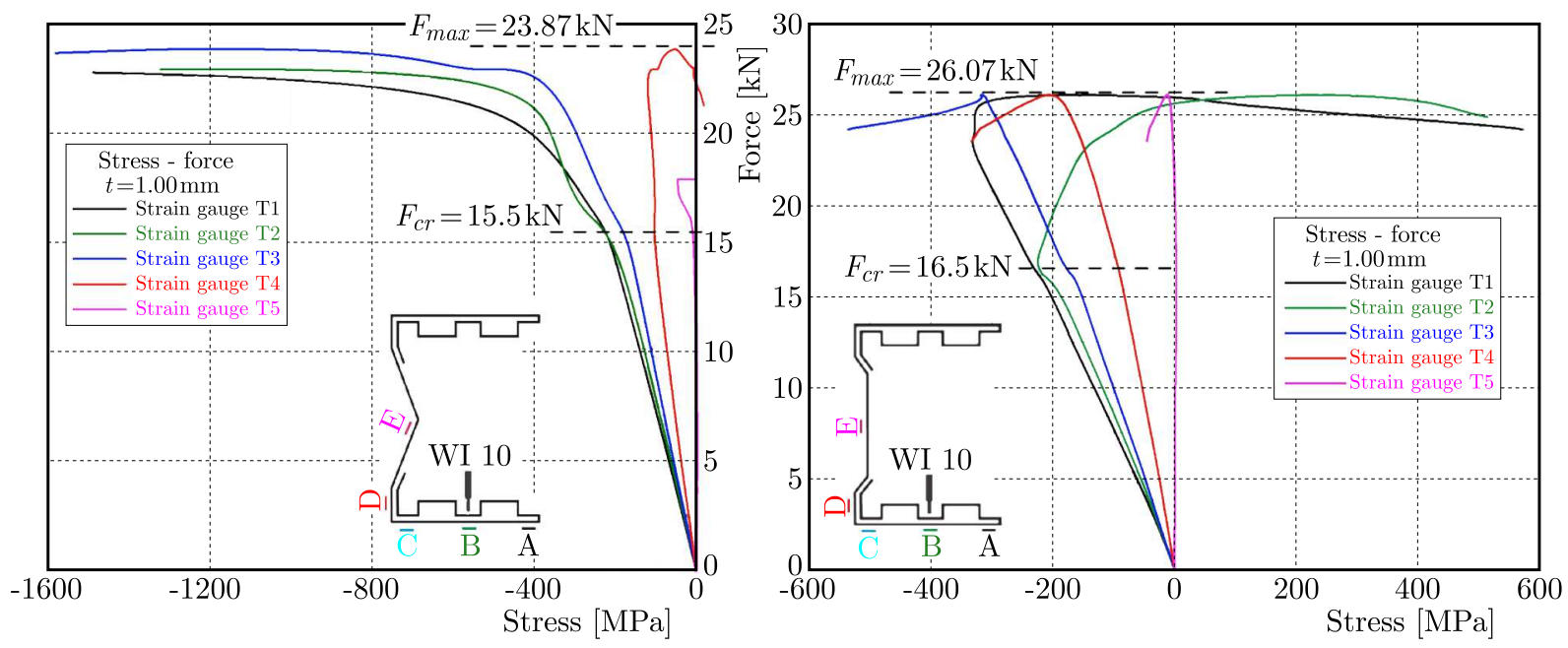

Fig. 13. The experimental critical and maximum load of beams B1-V and B2-S

maximum transverse dimension. In the considered case, the total length of the beam is $2000 \mathrm{~mm}$ and depth of the beam is $80 \mathrm{~mm}$, so this condition is met $(2000>15 \times 80 \mathrm{~mm}=1200 \mathrm{~mm})$. The length of the middle span of the beam subjected to pure bending (area between two point loads) should be between $20 \%$ and $33 \%$ of the total length of the beam $(20 \% \times 2000=400 \mathrm{~mm}$, $33 \% \times 2000 \mathrm{~mm}=660 \mathrm{~mm}$ ). The load is applied to the shear center of the beam and the beam is secured against local buckling, so it may collapse in the middle. The deflection of the beam is measured in the middle, in the places where the load is applied and at the ends. The longitudinal dimensions of the beams and the loading diagram are shown in Fig. 3.

The shape of the cross-section of the beams changes during tests. However, this is local and distortional buckling, and the load and deformation can increase until collapse. Therefore, the maximum force is much higher than the critical one. The difference between the critical loads of beams B1-V and B2-S is small, approx. $1 \mathrm{kN}$. Beams buckle locally when the relationship 
between stresses and load stops to be linear. This point/load in the graph (Fig. 13) is the critical load. Sometimes the deformation of the cross-section is not clearly visible.

The growth of displacements of cold-formed thin-walled beams subjected to increasing load causes local buckling that may interact with global buckling. In Fig. 14, the relationship between the force and deflection of the bottom flange is shown. It may be seen there that the maximum load of beam B2-S is bigger than in beam B1-V. The difference is $2.83 \mathrm{kN}$.

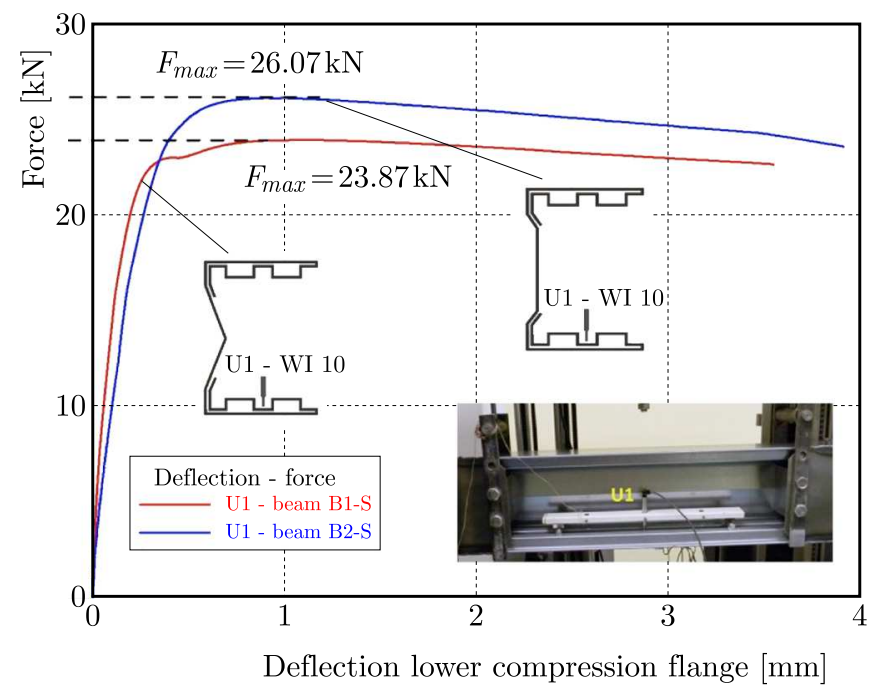

Fig. 14. The experimental relationship between the force and the deflection of the bottom flange (wall thickness $t=1.00 \mathrm{~mm}$ )

The presented results confirm that the load capacity of beams is generally restricted by local buckling. Firstly, the compressed flange buckles and then does the stiffened web. Some interactions between different buckling modes are observed as well. The summary of results, i.e. critical and experimental forces, is shown in Table 6 .

Table 6. The comparison of experimental and numerical results for wall thickness $t=1.00 \mathrm{~mm}$ (FSM and FEM)

\begin{tabular}{|c|c|c|c|c|}
\hline Cross- & \multirow{2}{*}{ Weight } & \multicolumn{3}{|c|}{ Investigations } \\
\cline { 3 - 5 } -sections & & Experimental & Numerical (the FSM) & Numerical (the FEM) \\
\hline \hline B1-V & $8.4 \mathrm{~kg}$ & $15.5 \mathrm{kN}$ & $16.7 \mathrm{kN}$ & $15.9 \mathrm{kN}$ \\
\hline B2-S & $10.0 \mathrm{~kg}$ & $16.5 \mathrm{kN}$ & $17.2 \mathrm{kN}$ & $16.9 \mathrm{kN}$ \\
\hline
\end{tabular}

\section{Conclusions}

The paper describes experimental and numerical investigations of cold formed thin-walled channel beams with a stiffened web. Two different open cross-sections of beams are examined. New cross-sections that have not been analysed before are be considered in this paper. The beams are subjected to pure bending, and their linear elastic stability and limit load are considered.

The aim of research is comparison of numerical results, obtained using the FEM and the FSM, with experimental ones. In that way both models (numerical and actual) simulating pure bending are validated. Numerical investigations make it possible to observe buckling modes of flanges and web including their interactions. The actual critical forces are difficult to measure because sometimes deformation, even during buckling (especially local one), is very small and unnoticeable. Moreover, it may appear in places other than those where strain gauges are located. 
This confirms that numerical simulations need to be done to prove if test stands simulating pure bending are built properly, e.g. where to place strain gauges. Moreover, they may give a better view on the structure than actual tests. On the other hand, the numerical model is based on some assumptions and simplifications. Therefore, the numerical results should be compared with the experimental ones to validate them.

In Table 6 the comparison of numerical (the FEM and the FSM) and experimental stresses is shown. They refer to beams B1-V and B2-S of wall thickness $t=1.00 \mathrm{~mm}$. In this case, numerical results seem to be a little bit lower (2-5\%) than the experimental ones.

The presented investigations lead to the following conclusions:

- this work presents two completely new and innovative high-strength cross-sections with box flanges and a stiffened web,

- numerical investigations are supplementary to experimental tests and, in some cases, may even give better results, e.g. when critical forces and local buckling modes are difficult to measure,

- the difference between numerical results (the FSM) and experimental ones is small and less than $2 \%$ in the case of beam B1-V $(t=1.00 \mathrm{~mm})$ and less than $5 \%$ in the case of beam $\mathrm{B} 2-\mathrm{S}(t=1.00 \mathrm{~mm})$,

- numerical and experimental buckling modes are similar and repeatable,

- during actual tests, when the value of the bending force exceeds the threshold, deformation of the cross-section and further buckling modes are observed as the load increases,

- the same deformation between the upper part of flanges and the corrugations (with boxes) has been observed in buckling modes obtained from the FSM and experimental investigations,

- the resistance of beam B2-S to local buckling is bigger than in beam B1-V,

- web buckles in the elastic range,

- the difference between experimental critical forces of beams B1-V and B2-S is less than $7 \%$.

The obtained results confirm that there is still a need to search for new shapes of cross-sections of thin-walled cold-formed channel beams.

\section{Acknowledgements}

The project was funded by the National Science Centre allocated on the basis of the decision No. DEC-2017/25/B/ST8/00266 of 2017-11-23 - Contract No. UMO-2017/25/B/ST8/00266.

\section{References}

1. ÁdÁNy S., Joó A.L., Schafer B.W., 2010, Buckling mode identification of thin-walled members by using cFSM base functions, Thin-Walled Structures, 48, 806-817

2. ÁdÁNy S., Schafer B.W., 2006, Buckling mode decomposition of single-branched open cross-section members via finite strip method: Derivation, Thin-Walled Structures, 44, 563-584

3. Bамвасн M.R., 2009, Photogrammetry measurements of buckling modes and interactions in channels with edge-stiffened, Thin-Walled Structures, 47, 485-504

4. BeregszÁsZi Z., ÁDÁNy S., 2009, The effect of rounded corners of cold-formed steel members in the buckling analysis via the direct strength method, Proceedings of the Twelfth International Conference on Civil, Structural and Environmental Engineering Computing, Paper 36

5. Biegus A., Czepiżak D., 2008, Experimental investigations on combined resistance of corrugated sheets with strengthened cross-sections under bending and concentrated load, Thin-Walled Structures, 46, 303-309 
6. CEN, European Committee for Standardisation, 2006, EN 1993-1-3: Eurocode 3 - Design of Steel Structures, Part 1-3: General rules - Supplementary rules for cold-formed members and sheeting

7. Chu T.X., Ye Z., Li L., Kettle R., 2006, Local and distortional buckling of cold-formed zedsection beams under uniformly distributed transverse loads, International Journal of Mechanical Sciences, 48, 378-388

8. Djafour M., Djafour N., Megnounif A., Kerdal D.E., 2010, A constrained finite strip method for open and closed cross-section members, Thin-Walled Structures, 48, 955-965

9. Gonçalves R., Ritto-Corrêa M., Camotim D., 2010, A large displacement and finite rotation thin-walled beam formulation including cross-section deformation, Computer Methods Applied Mechanics and Engineering, 199, 1627-1643

10. Ibrahim S.M., Carrera E., Petrolo M., Zappino E., 2012, Buckling of thin-walled beams by a refined theory, Journal of Zhejiang University - Science A (Applied Physics and Engineering), 13, 10, 747-759

11. Kwon Y.B., Kim B.S, Hancock G.J., 2009, Compression tests of high strength cold-formed steel channels with buckling interaction, Journal of Constructional Steel Research, 65, 278-289

12. Li Z., Schafer B.W., 2010, Application of the finite strip method in cold-formed steel member design, Journal of Constructional Steel Research, 66, 971-980

13. Mahendran M., Jeyaragan M., 2008, Experimental investigation of the new built-up lite steel beams, Proceedings of 5th International Conference on Thin-Walled Structures, 433-441

14. Obst M., Kurpisz D., Paczos P., 2016, The experimental and analytical investigations of torsion phenomenon of thin-walled cold formed channel beams subjected to four-point bending, ThinWalled Structures, 106, 179-186

15. Paczos P., 2013, Experimental and numerical (FSM) investigations of thin-walled beams with double-box flanges, Journal of Theoretical and Applied Mechanics, 51, 2, 497-504

16. PAczos P., 2014, Experimental investigations of thin-walled C-beams with nonstandard flanges, Journal of Constructional Steel Research, 93, 77-87

17. Pastor M.M., Roure F., 2008, Open cross-section beams under pure bending. I. Experimental investigations, Thin-Walled Structures, 46, 476-483

18. Schafer B.W., 2002, Local, Distortional and Euler buckling of thin-walled columns, Journal of Structural Engineering, 128, 3, 289-299

19. Schafer B.W., 2006, Designing cold-formed steel using the direct strength method, 18-th International Specialty Conference on Cold-Formed Steel Structures

20. SolidWorks 2011 SP5, Solid v Corporation Headquarters, 175 Wyman Street Waltham, MA 02451, 800-693-9000 US and Canada

21. Yu C., Schafer B.W., 2007, Simulation of cold-formed steel beams in local and distortional buckling with applications to the direct strength method, Journal of Constructional Steel Research, 63, 581-590 